Research article

\title{
The (CTG)n polymorphism in the NOTCH4 gene is not associated with schizophrenia in Japanese individuals Koubun Imai*1 ${ }^{* 1}$ Shoji Harada ${ }^{2}$, Yoichi Kawanishi ${ }^{1}$, Hirokazu Tachikawa ${ }^{1}$, Takehito Okubo ${ }^{2}$ and Toshihito Suzuki ${ }^{1}$
}

\author{
Address: ${ }^{1}$ Department of Psychiatry, Institute of Clinical Medicine, University of Tsukuba, Tsukuba City, Ibaraki, Japan and ${ }^{2}$ Institute of \\ Community Medicine, University of Tsukuba, 1-1-1 Tennoudai, Tsukuba City, Ibaraki 305-8575, Japan \\ E-mail: Koubun Imai* - zc6k-imi@asahi-net.or.jp; Shoji Harada - sjharada@md.tsukuba.ac.jp; Yoichi Kawanishi - qb2y-kwns@asahi- \\ net.or.jp; Hirokazu Tachikawa - mg8@ea.mbn.or.jp; Takehito Okubo - ta-okubo@bc4.so-net.ne.jp; \\ Toshihito Suzuki - psuzukit@md.tsukuba.ac.jp \\ *Corresponding author
}

Published: 4 June $200 \mathrm{I}$

BMC Psychiatry 200I, I:I

This article is available from: http://www.biomedcentral.com/I47I-244X/I/I

(c) 200 I Imai et al, licensee BioMed Central Ltd.
Received: 18 April 200।

Accepted: 4 June 2001

\begin{abstract}
Background: The human NOTCH4 gene is a candidate gene for schizophrenia due to its chromosomal location and neurobiological roles. In a British linkage study, NOTCH4 gene polymorphisms were highly associated with schizophrenia. In a Japanese case-control association study, however, these polymorphisms did not show significant associations with schizophrenia. We conducted a case-control study with Japanese subjects to explore an association between the triplet repeat polymorphism in the NOTCH4 gene and schizophrenia, including subtypes of schizophrenia, longitudinal disease course characteristics, and a positive family history for psychoses.
\end{abstract}

Methods: We examined the (CTG)n repeat polymorphism in the NOTCH4 gene among 100 healthy Japanese individuals and 102 patients with schizophrenia (22 paranoid, 38 disorganized, 29 residual, 64 episodic, 3 I continuous, 42 with prominent negative symptoms, and 46 with positive family histories) using a polymerase chain reaction-based, single-strand conformational polymorphism analysis.

Results: Five different alleles consisting of $6,9,10,1 \mathrm{I}$, and I 3 repeats of CTG (Leu) in patients with schizophrenia, and 4 alleles consisting of $6,9,10$, and II repeats in controls were found. No significant differences in genotype or allele frequencies of repeat numbers were found between controls and patients. In addition, there were no associations between the polymorphism and schizophrenia subtypes, longitudinal disease course characteristics, or positive family history of the patients.

Conclusions: Our data suggest a lack of association between the NOTCH4 gene triplet repeat polymorphism and schizophrenia in Japanese individuals.

\section{Background}

NOTCH activity affects the implementation of differentiation, proliferation, and apoptotic programs, influencing organ formation and morphogenesis [1]. The formation of neuronal contacts results in activation of NOTCH receptors, leading to the restriction of neuronal growth and 
a subsequent arrest in differentiation [2]. NOTCH functions as a genetic switch between neuronal and glial fates through its negative regulation of the glial cell deficient/ glial cells missing (glide $/ \mathrm{gcm}$ ) gene, the gene required to induce gliogenesis in glial precursors [3].

The human $\mathrm{NOTCH}_{4}$ gene is located on chromosome 6p21.3 [4], and several linkage studies have suggested that a susceptibility locus for schizophrenia is present on chromosome $6 \mathrm{p}[5,6,7,8]$. In situ hybridization studies have determined that in embryonic and adult life, $\mathrm{NOTCH}_{4}$ transcripts are primarily restricted to endothelial cells [9]. NOTCH4 is not necessary for embryonic development, as $\mathrm{NOTCH}_{4}$-deficient mice develop normally. However, this gene and the NOTCH1 gene have partially overlapping roles during embryogenesis in mice; both NOTCH1-mutant and NOTCH1/NOTCH4double mutant embryos have severe defects in angiogenic vascular remodeling [10].

Using linkage disequilibrium mapping of the human major histocompatibility complex (MHC) region in 80 British parent-offspring trios, Wei and Hemmings [11] found that $\mathrm{NOTCH}_{4}$ was highly associated with schizophrenia. The A-to-G substitution in the promoter region ( $\mathrm{SNP} 2)$ and the (CTG)n repeat in exon 1 of NOTCH4 were considered possible candidate sites conferring susceptibility. A Japanese case-control association study [12] reported that these polymorphisms did not show significant associations with schizoaffective disorder or schizophrenia in Japanese individuals; further, no associations were found between the polymorphisms and subcategories of schizophrenia or a positive family histry of psychoses.

We conducted a case-control study using Japanese subjects to explore an association between the (CTG)n repeat polymorphism in the NOTCH4 gene and schizophrenia, and to examine subtypes, longitudinal disease course characteristics, and a positive family history of psychoses. We found no association between the NOTCH4 gene triplet repeat polymorphism and schizophrenia in this patient population.

\section{Methods \\ DNA Samples}

Informed written consent was obtained from subjects prior to the study according to research protocols approved by the Ethics Committee of Tsukuba University. Schizophrenic patients $(\mathrm{N}=102)$ were examined; this group consisted of 61 men (mean age, $46.2 \pm 12.0$ years; mean age at onset of schizophrenia, 25.2 \pm 7.4 years) and 41 women (mean age, $47.5 \pm 15.5$ years; mean age at onset of schizophrenia, $27.0 \pm 10.6$ years) who matched the DSM-IV criteria for schizophrenia [13]. Patients were further divided into subtypes (22 paranoid, 38 disorganized, 4 catatonic, 29 residual, and 9 undifferentiated), and classified as to longitudinal course specifiers (64 episodic, 31 continuous, 5 single episode, and 2 other or unspecified). Furthermore, 42 patients were categorized with prominent negative symptoms, and 46 patients had a family history of psychoses in first- or second-degree relatives.

The control group consisted of 100 unrelated healthy volunteers (30 men, mean age $32.1 \pm 11.4$ years and 70 women, mean age $43.1 \pm 12.0$ years) who were hospital employees living in the same city as the patients. Each volunteer was interviewed by 2 psychiatrists in order to rule out subjects with a family history of mental illness. All patients and controls were of Japanese origin.

Genomic DNA samples were prepared from whole blood collected in disodium ethylenediamine tetra-acetic acid (EDTA; $3 \mathrm{mg} / \mathrm{L}$ ) according to the sodium iodide method (DNA Extractor WB Kit, Wako Pure Chemical Industries, Osaka, Japan).

\section{Polymerase Chain Reaction Conditions}

A set of polymerase chain reaction (PCR) primers that spanned the (CTG)n repeat region in exon 1 was used to produce DNA fragments. The primers used were NOTLR-F (forward): 5'-CCCTGCCTGAAGAGGGACAG-3' and NOT-LR-R (reverse): 5'-TCTGGGTCTGACCACTGAGAC-3'. These primers were designed using information from a previous report [4] and the GenBank sequence (accession number: U89335). The 5 '-terminus of NOT-LR-F was labeled with indodicarbocyanine fluorescent dye (Amersham Pharmacia Biotech, Uppsala, Sweden) for fluorescence-based, single-strand conformational polymorphism (SSCP) analysis.

The PCR mixture contained the following: $0.5 \mathrm{ng}$ genomic DNA, $0.25 \mu \mathrm{M}$ of each primer, $0.2 \mathrm{mM}$ of each deoxynucleotide triphosphate, $10 \mathrm{mM}$ Tris- $\mathrm{HCl}$ ( $\mathrm{pH} 8.3), 50$ $\mathrm{mM} \mathrm{KCl,} 1.5 \mathrm{mM} \mathrm{MgCl}_{2}$, and $0.5 \mathrm{U}$ of Taq DNA polymerase (HotStarTaq, QIAGEN, Hilden, Germany) in a final volume of $25 \mu \mathrm{l}$.

The amplification reaction was performed as follows: an initial denaturation at $95^{\circ} \mathrm{C}$ for 15 minutes, followed by 35 cycles of denaturation at $94^{\circ} \mathrm{C}$ for 30 seconds, annealing at $62^{\circ} \mathrm{C}$ for 30 seconds, and extension at $72^{\circ} \mathrm{C}$ for 30 seconds, with a final extension step of $72^{\circ} \mathrm{C}$ for $10 \mathrm{~min}$ utes (GeneAmp 9600, PE Applied Biosystems, Foster City, CA).

PCR products were visualized by ethidium bromide staining under UV light after electrophoresis on $2 \%$ agarose gels. 
Table I: Allele frequencies of the CTG repeat in controls and schizophrenic patients, including subtypes, course specifiers and positive family history, and results of Fisher's exact test and Monte Carlo method

\begin{tabular}{|c|c|c|c|c|c|c|c|}
\hline \multirow{3}{*}{ Subjects (n) } & \multirow{2}{*}{\multicolumn{5}{|c|}{ Alleles (\%) }} & \multirow{3}{*}{$\begin{array}{c}\text { Fisher's test } \\
\text { 6R vs 9-13R } \\
\text { P value }\end{array}$} & \multirow{3}{*}{$\begin{array}{c}\text { Monte Carlo } \\
\text { method } \\
\text { P value }\end{array}$} \\
\hline & & & & & & & \\
\hline & $6 R$ & $9 \mathrm{R}$ & IOR & IIR & I3R & & \\
\hline Controls (100) & $38(19.0)$ & $72(36.0)$ & $78(39.0)$ & $12(6.0)$ & $0(0.0)$ & 0.7095 & 0.9547 \\
\hline Schizophrenic patients (102) & $42(20.6)$ & $67(32.8)$ & $80(39.2)$ & $14(6.9)$ & $\mathrm{I}(0.5)$ & 0.7095 & 0.9547 \\
\hline \multicolumn{8}{|l|}{ Subtypes } \\
\hline Paranoid (22) & $10(22.7)$ & $13(29.5)$ & $17(38.6)$ & $4(9.1)$ & $0(0.0)$ & 0.5378 & 0.7538 \\
\hline Disorganized (38) & $21(27.6)$ & $27(35.5)$ & $23(30.3)$ & $4(5.3)$ & $\mathrm{I}(\mathrm{I} .3)$ & 0.1392 & 0.3808 \\
\hline Residual (29) & $8(13.8)$ & $18(31.0)$ & $28(48.3)$ & $4(6.9)$ & $0(0.0)$ & 0.4386 & 0.6666 \\
\hline Others (13) & $3(11.5)$ & $9(34.6)$ & $12(46.1)$ & $2(7.7)$ & $0(0.0)$ & 0.4304 & 0.7869 \\
\hline \multicolumn{8}{|l|}{ Course } \\
\hline Episodic (64) & $24(18.8)$ & $48(37.5)$ & $45(35.2)$ & $10(7.8)$ & $\mathrm{I}(0.8)$ & 1.0000 & 0.9207 \\
\hline Continuous (3I) & $15(24.2)$ & $15(24.2)$ & $28(45.2)$ & $4(6.5)$ & $0(0.0)$ & 0.3709 & 0.4709 \\
\hline Others (7) & $3(21.4)$ & $4(28.6)$ & $7(50.0)$ & $0(0.0)$ & $0(0.0)$ & 0.7346 & 0.8137 \\
\hline Prominent negative symptoms (42) & $17(20.2)$ & $26(31.0)$ & $34(40.5)$ & $6(7.1)$ & $\mathrm{I}(\mathrm{I} .2)$ & 0.8696 & 0.8388 \\
\hline Positive family history (46) & $19(20.7)$ & $31(33.7)$ & $34(37.0)$ & $7(7.6)$ & $\mathrm{I}(\mathrm{I} . \mathrm{I})$ & 0.7522 & 0.9002 \\
\hline
\end{tabular}

$6 R, 9 R, I O R, I I R$ and I $3 R$ indicate $6,9,10, I I$ and $I 3$ repeats of CTG, respectively.

\section{SSCP Analysis}

A DNA sequencer (ALF express, Amersham Pharmacia Biotech) was used to perform fluorescence-based SSCP analysis. PCR products were mixed with loading buffer containing $99.5 \%$ deionized formamide and $0.5 \%$ blue dextran. The solution was denatured at $97^{\circ} \mathrm{C}$ for $5 \mathrm{~min}-$ utes, then immediately cooled on ice. Single-stranded PCR products were analyzed by electrophoresis on $7 \%$ polyacrylamide gels (49:1, acrylamide:bisacrylamide ratio) containing $7 \mathrm{M}$ urea in $0.5 \mathrm{X}$ Tris-borate-EDTA buffer at $50^{\circ} \mathrm{C}$. The data were analyzed using the software package Fragment Manager (Amersham Pharmacia Biotech).

\section{PCR Product Sequencing}

PCR products showing altered band patterns by SSCP analysis were purified by centrifugation to recover the DNA (Microcon tube, Millipore, Bedford, MA). DNA sequences of the PCR products were directly determined using a Genetic Analyzer (ABI PRISM TM 310, PE Applied Biosystems) after termination-dideoxy-cycle sequencing (Sequencing Reaction Kit-FS, PE Applied Biosystems) with the forward primer (NOT-LR-F).

\section{Statistical Analysis}

Deviation of genotype distribution as derived from the Hardy-Weinberg equilibrium equation was calculated using the chi-square test for goodness of fit. Association analyses were performed using Fisher's exact probability test (2-sided) using InStat-2.01 (GraphPad Software, San Diego, CA). Simulations using the Monte Carlo method [14] were performed using ARLEQUIN (version 2.00, University of Geneva) software.

\section{Results and Discussion}

A triplet repeat (CTG)n polymorphism in the $\mathrm{NOTCH}_{4}$ gene was identified by SSCP analysis and confirmed by direct sequencing of PCR products. As shown in Table 1, 
5 different alleles consisting of 6, 9, 10, 11, and 13 repeats (6R, 9R, 10R, 11R, and 13R) of CTG (Leu) in patients with schizophrenia, and 4 alleles consisting of $6 \mathrm{R}, 9 \mathrm{R}, 10 \mathrm{R}$, and $11 \mathrm{R}$ in controls were found. No significant differences in genotype or allele frequencies of repeat numbers were found between controls and patients. In addition, there were no associations between the polymorphism and subtypes, longitudinal disease course characteristics, or family history of psychoses.

The British linkage study [11] revealed that an excess of the $(\mathrm{CTG})_{10}$ allele was transmitted to affected offspring by their parents. In our comparison of the frequency of the $10 R$ allele with the other alleles $(6 R+9 R+11 R+13 R)$, no significant differences were found between controls and patients with schizophrenia.

Previous study [12] and our study using random samples found no association between the polymorphism and schizophrenia. Possible reasons for disagreement with the British study [11] depend on the differences of ethnicity, population admixture, sample size and methodology. Wei and Hemmings [11] used the Transmission Disequilibrium Test, while our study employed a case-control design, which might produce false positive or negative findings due to stratification problems [15]. Further study using a larger sample size and the investigation of more SNPs in coding regions will be necessary to confirm the relationship between the $\mathrm{NOTCH}_{4}$ gene and schizophrenia.

\section{Conclusions}

Our study suggests a lack of association between the triplet repeat (CTG)n polymorphism in the $\mathrm{NOTCH} 4$ gene and schizophrenia in Japanese patients.

\section{List of abbreviations used \\ NOTCH1,4; Notch (Drosophila) homolog of 1, 4}

SNP; single nucleotide polymorphism

DSM-IV; diagnostic and statistical manual of mental disorders, 4 th edn

PCR; polymerase chain reaction

SSCP; single-strand conformational polymorphism

\section{Competing interests}

None declared

\section{References}

I. Artavanis-Tsakonas S, Rand MD, Lake RJ: Notch signaling: Cell fate control and signal integration in development. Science 1999, 284:770-776
2. Sestan N, Artavanis-Tsakonas S, Rakic P: Contact- dependent inhibition of cortical neurite growth mediated by Notch signaling. Science 1999, 286:74I-746

3. Van De Bor $V$, Giangrande A: Notch signaling represses the glial fate in fly PNS. Development 200 I, I 28: I38I-1390

4. Sugaya K, Sasanuma S, Nohata J, Kimura T, Fukagawa T, Nakamura Y, Ando A, Inoko H, lkemura T, Mita K: Gene organization of human NOTCH4 and (CTG)n polymorphism in this human counterpart gene of mouse proto-oncogene Int3. Gene 1997, 189:235-244

5. Moises HW, Yang L, Kristbjarnarson H, Wiese C, Byerley W, Macciardi F, Arolt V, Blackwood D, Liu X, Sjögren B, et al: An international two-stage genome-wide search for schizophrenia susceptibility genes. Nat Genet 1995, I I:32 I-324

6. Wildenauer DB, Schwab SG, Albus M, Hallmayer J, Lerer B, Maier W Blackwood D, Muir W, St Clair D, Morris S, et al: Additional support for schizophrenia linkage on chromosome 6 and 8: A multicenter study. Am J Med Genet 1996, 67:580-594

7. Nurnberger Jr Jl, Foroud T: Chromosome 6 workshop report. Am J Med Genet 1999, 88:233-238

8. Hwu HG, Lin MW, Lee PC, Lee SFC, Ou-Yang WC, Liu CM: Evaluation of linkage of markers on chromosome $6 \mathrm{p}$ with schizophrenia in Taiwanese families. Am J Med Genet 2000, 96:74-78

9. Uyttendaele H, Marazzi G, Wu G, Yan Q, Sassoon D, Kitajewski J: Notch4/int-3, a mammary proto-oncogene, is an endothelial cell-specific mammalian Notch gene. Development 1996 I 22:225I-2259

10. Krebs LT, Xue Y, Norton CR, Shutter JR, Maguire M, Sundberg JP, Gallahan D, Closson V, Kitajewski J, Callahanm R, et al: Notch signaling is essential for vascular morphogenesis in mice. Genes Dev 2000, 14:1343-1352

II. Wei J, Hemmings GP: The NOTCH4 locus is associated with susceptibility to schizophrenia. Nat Genet 2000, 25:376-377

12. Ujike H, Takehisa Y, Takaki M, Tanaka Y, Nakata K, Takeda T, Kodama M, Fujiwara Y, Yamamoto A, Kuroda S: NOTCH4 gene polymorphism and susceptibility to schizophrenia and schizoaffective disorder. Neurosci Lett 200I, 301:41-44

13. Diagnostic and statistical manual of mental disorders, 4th edn. American Psychiatric Association, Washington, DC 1994 273-3I5

14. Raymond M, Rousett F: An exact test for population differentiation. Evolution 1995, 49:1280-1287

15. Kidd KK: Associations of disease with genetic markers: Déjà vu all over again. Am J Med Genet 1993, 48:71-73

\section{Pre-publication history}

The pre-publication history for this paper can be accessed here:

http://www.biomedcentral.com/content/backmatter/ 1471-244X-1-1-b1.pdf

Publish with BioMedcentral and every scientist can read your work free of charge

"BioMedcentral will be the most significant development for disseminating the results of biomedical research in our lifetime." Paul Nurse, Director-General, Imperial Cancer Research Fund

Publish with BMc and your research papers will be:

- available free of charge to the entire biomedical community

- peer reviewed and published immediately upon acceptance

- cited in PubMed and archived on PubMed Central

- yours - you keep the copyright

Submit your manuscript here:

http://www.biomedcentral.com/manuscript/

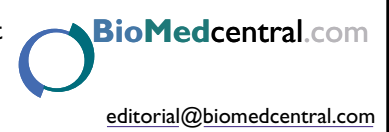

